\title{
latrogenic perforation during colonoscopy in the endoscopic suturing era: surgical emergency or endoscopic clinical practice?
}

A 46-year-old man with end-stage renal disease and a surgical history of three kidney transplants underwent colonoscopy to assess eligibility for retransplantation. Water exchange $\mathrm{CO}_{2}$-insufflated colonoscopy was performed under deep sedation.

After traversing about $50 \mathrm{~cm}$ of the fixed and acutely angulated sigmoid colon, an iatrogenic perforation was promptly recognized: a transmural wall defect $20 \mathrm{~mm}$ in diameter ( $\mathbf{F i g . 1}$ ). Broad-spectrum antibiotic therapy was started. After a prompt multidisciplinary evaluation, immediate endoscopic closure under general anesthesia was planned ( $\downarrow$ Video 1 ).

The perforation site was reached with a double-channel endoscope (GIF2T160; Olympus Europe, Hamburg, Germany). Endoscopic peritoneal exploration was done in order to rule out leaked luminal contents and visceral injuries.

An angiocatheter attached to a syringe half-filled with normal saline was percutaneously inserted under direct endoscopic view for capnoperitoneum man-

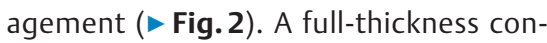
tinuous suture incorporating an omental flap was performed using the OverStitch suturing device (Apollo Endosurgery,

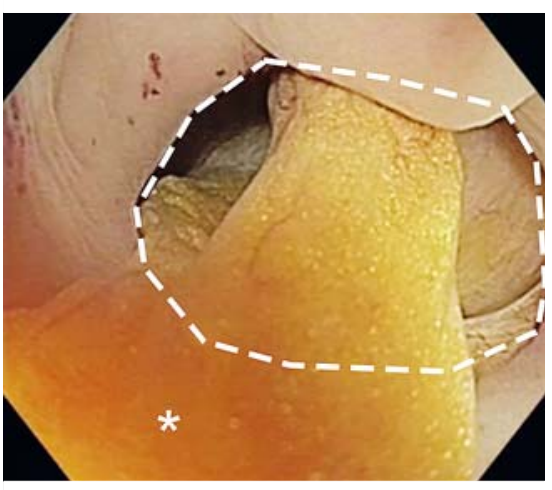

- Fig. 1 Sigmoid colon iatrogenic perforation (white dashed line) with a visible fragment of omentum (asterisk).
Austin, Texas, USA), thus creating an omental patch endoscopically.

The complete closure was confirmed by full luminal distension restoration and by the negative air-leak pressure test. Furthermore, neither contrast medium nor $\mathrm{CO}_{2}$ extravasation was observed on fluoroscopy. The angiocatheter was extracted after removal of all residual peritoneal gas.
Over the subsequent 48 hours, broadspectrum antibiotics, fluid replacement, and fasting were prescribed. The patient remained asymptomatic: the physical examination was negative for signs of peritonitis and the bowel remained canalized. Abdominal computed tomography performed on Day 2 showed intact anastomotic site without free fluid collections ( $\triangleright$ Fig.3). Oral feeding was resumed, and

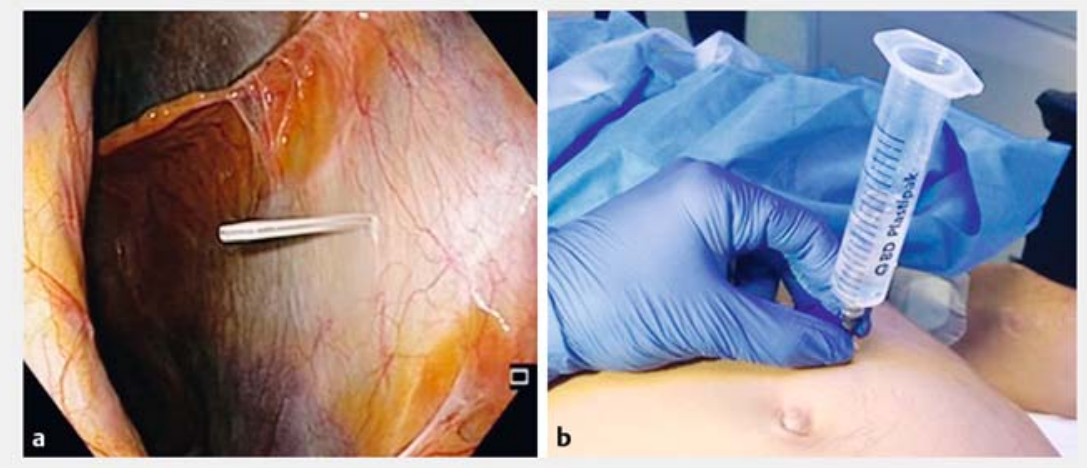

Fig. 2 Percutaneous insertion of an angiocatheter under endoscopic view for capnoperitoneum management. a Focus on the cannula into the peritoneal cavity. $\mathbf{b}$ The connected syringe half-filled with sterile saline solution and visible bubble inside.

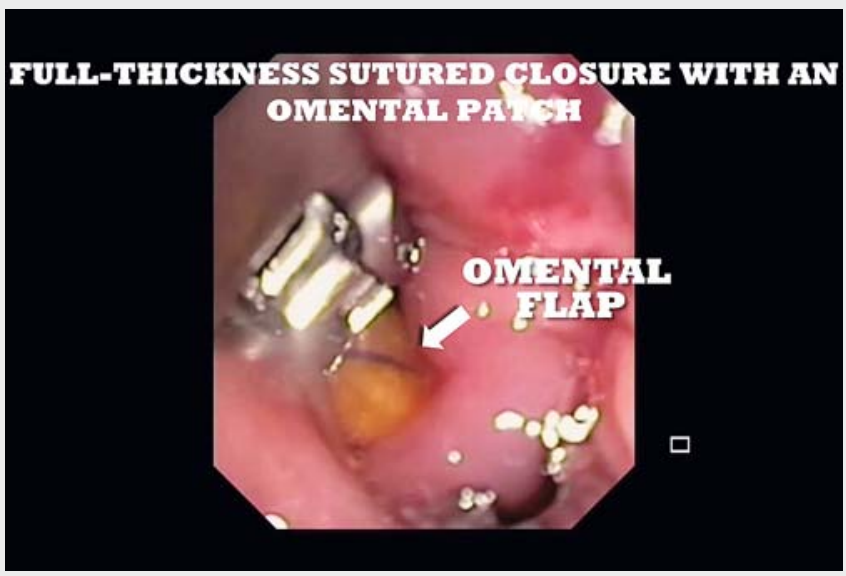

$\checkmark$ Video 1 Simultaneous endoscopic full-thickness closure of an iatrogenic sigmoid perforation after diagnostic colonoscopy. 


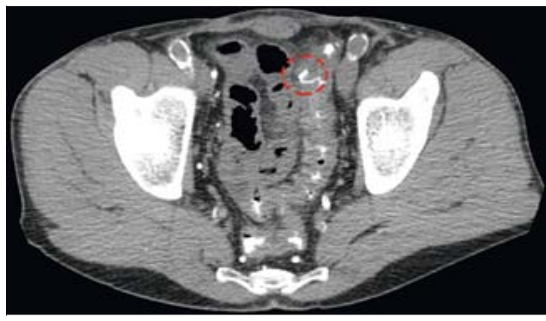

- Fig. 3 Abdominal computed tomography showing intact anastomotic site (red dashed line) with no evidence of leakage.

the patient was discharged on the following day.

Colonic perforations are potentially lifethreatening complications of both diagnostic and therapeutic colonoscopies, with a reported incidence of $0.03 \%$ $0.8 \%$ and up to $5 \%$, respectively [1]. The sigmoid colon is the most common perforation site during diagnostic procedures [2]. The availability of full-thickness endoscopic suturing systems can help to confine surgery to highly selected cases.

Endoscopy_UCTN_Code_CPL_1AJ_2AB
None

The authors

Antonino Granata ${ }^{1}$, Michele Amata ${ }^{1}$, Alberto Martino', Dario Ligresti ${ }^{1}$, Alessandro Tropea ${ }^{2}$, Serio Calamiaㄹ, Mario Traina ${ }^{1}$

1 Digestive Endoscopy Service, Department of Diagnostic and Therapeutic Services, IRCCS - ISMETT, Palermo, Italy

2 Abdominal Surgery and Organ Transplantation Unit, Department for the Treatment and Study of Abdominal Diseases and Abdominal Transplantation, IRCCS ISMETT, Palermo, Italy

Corresponding author

Antonino Granata, MD

Endoscopy Service, IRCCS - ISMETT, Via

Tricomi 5, 90127 Palermo, Italy

Fax: +39-091-2192400

agranata@ismett.edu
References

[1] Paspatis GA, Dumonceau JM, Barthet M et al. Diagnosis and management of iatrogenic endoscopic perforations: European Society of Gastrointestinal Endoscopy (ESGE) Position Statement. Endoscopy 2014; 46: 693 711

[2] Lüning TH, Keemers-Gels ME, Barendregt WB et al. Colonoscopic perforations: a review of 30,366 patients. Surg Endosc 2007; 21: $994-997$

\section{Bibliography}

DOI https://doi.org/10.1055/a-0948-3960

Published online: 1.7.2019

Endoscopy 2019; 51: E366-E367

(c) Georg Thieme Verlag KG

Stuttgart · New York

ISSN 0013-726X

\section{ENDOSCOPY E-VIDEOS}

https:/|eref.thieme.de/e-videos

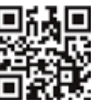

Endoscopy E-Videos is a free access online section, reporting on interesting cases and new

techniques in gastroenterological endoscopy. All papers include a high quality video and all contributions are freely accessible online.

This section has its own submission website at

https://mc.manuscriptcentral.com/e-videos 